\title{
ASSESSMENT OF TRACK QUALITY IN TRIAL TEST SECTIONS BY SPOT AND CONTINUOUS METHOD
}

\begin{abstract}
The quality of track alignment and track geometry is an essential precondition of safe and economical operation of railway track. The paper provides an analysis of diagnostics of relative track geometry parameters and evaluation of measurement deviations carried out by the spot and continuous method in sections of the ballasted track, transition areas and sections with the slab track structure.
\end{abstract}

Keywords: Railway track, ballasted track, ballastless track, slab track, track geometry, diagnostics.

\section{Introduction}

The ballasted track has been proven for many decades. From the structural point of view, the ballasted track is referred to as a railway track whose track skeleton is stored in railway ballast. In the case of high line tonnage and axle load and increasing track speeds, it appears that such a structure has its operational and economical limits [1]. The ballasted track is characterized by "floating" placement of track skeleton which causes the growth of dynamic forces during each passage of a train. This can be and usually is the cause of gradual degradation of the track geometry. The need of elimination of irregularities in the track geometry forces the operator to regularly remove the diagnosed track deficiencies by time-consuming and costly maintenance works. This phenomenon grows with increasing track speed and thus increases the maintenance costs and the share of track possessions. In this way the attractiveness of the track for passengers can be reduced. It is sufficient, however, to only replace the weakest structural element of the ballasted track - the track ballast by another more suitable structural element which shows no plastic behavior. The term slab track, as defined in [2], refers to such a structure of railway superstructure in which a spread function of railway ballast is replaced by reinforced materials, and which is placed on a concrete or asphalt substructure (slab). The slab track structure consists of (top-down):

- track superstructure

- rails and fastenings of the rails to the rail support,

- rail support (sleepers, single supporting points, prefabricated or monolithic slab),

- concrete foundation layer $(C F L)$ or asphalt foundation layer $(A F L)$,
- $\quad$ hydraulically bonded foundation layer $(H B L)$;

- track substructure (if the slab track construction is built on earthworks)

- frost protective layer (FPL),

- subsoil layers (consolidated or improved material of earthworks),

- consolidated soil or bedrock.

\section{Experimental section parameters}

The experimental sections are situated on the modernized double-track railway line Nove Mesto nad Vahom - Puchov and are located in the areas of the portals of the tunnel Turecky vrch. The track speed in both tracks is $160 \mathrm{~km} \cdot \mathrm{h}^{-1}$, which ranks the railway line to the category of velocity range No. 4 (RP4). The superstructure of each section is constructed as a construction with ballast bed and the slab track RHEDA $2000^{\circledR}$ (in tunnel, on bridges and on earthwork). The construction of the superstructure in transition areas is constructed as improved ballast placed in the concrete trough.

The monitoring of the track geometry aims to determine the condition of the parts of the track structure and the entire track. This kind of monitoring is one of the basic diagnostic activities by which also the traffic and climatic load and the effects of maintenance on track skeleton are monitored.

The experimental track sections are labeled as [3]:

- section 1.1 (track No. 1, south portal of the tunnel Turecky $v r c h$ ) and 2.1 (track No. 2, south portal; both sectors of length

175 m; km 102.360000 - km 102.535000 ):

\footnotetext{
* Michal Smalo, Libor Izvolt

Department of Railway Engineering and Track Management, Faculty of Civil Engineering, University of Zilina, Slovakia

E-mail: michal.smalo@fstav.uniza.sk
} 
- $\quad$ km 102.360000 - km 102.460500 structure with ballast bed,

- $\quad \mathrm{km} 102.460500$ - km 102.480500 structure with ballast bed in the concrete trough,

km 102.480500 - km 102.535000 slab track;

- section1.2 (track No. 1, north portal of the tunnel Turecky $v r c h$ ) and 2.2 (track No. 2, north portal); both sectors of length $640 \mathrm{~m}$; km 104.200000 - km 104.840 000):

- $\mathrm{km} 104.200000$ - km 104.720500 slab track,

- $\quad$ km 104.720500 - km 102.480500 structure with ballast bed in the concrete trough,

- $\quad \mathrm{km} 104.740500$ - km 104.840000 structure with ballast bed.

\section{Diagnostic methods and equipment}

The diagnostics of the track alignment design and track geometry by the spot method is realized by gauge-checkers $R O B E L$ (Fig. 1) and GEISMAR. The spot method is used to control deviations of gauge $\triangle R K(\mathrm{~mm})$ and cant $P K(\mathrm{~mm})$ and monitoring is performed at each fastening point of the rail support [4].

For the sake of comprehensive diagnostics, each section No. 1.1 and No. 2.1 is represented by 288 samples (fixation points) and each section No. 1.2 and No. 2.2 is represented by 1009 samples (fixation points) [5].

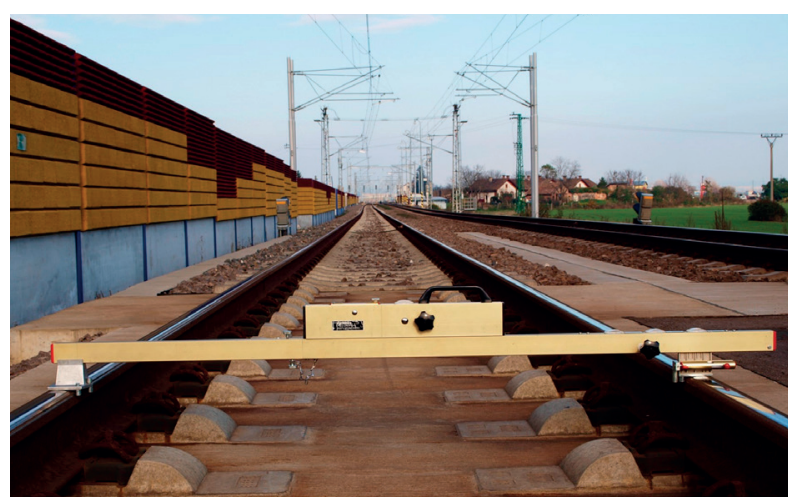

Fig. 1 Gauge checker ROBEL

The comprehensive diagnostics of the track alignment design and track geometry by continuous method is carried out by continuously measuring trolley $K R A B^{T M}$-Light (Fig. 2). The measurement is referred to as continuous, but in fact, the data is recorded with the measuring step of $250 \mathrm{~mm} \mathrm{[5]} \mathrm{and} \mathrm{[6]:}$

- gauge deviation $R K$ (after calculating the change of gauge $Z R$ is also recorded),

- alignment of right rail $S R$ (after calculating the alignment of left rail $S L$ is also recorded),

- rail top level of right rail st $V R$ (after calculating the rail top level of left rail $V L$ is also recorded),
- cant $P K$,

- quasi-twist on a short base (calculated to a quasi-twist on a base of $1.8 \mathrm{~m}$ long $-Z K 1.8$, on a base of $6.0 \mathrm{~m}$ long $-Z K 6.0$ and on a base of $12.0 \mathrm{~m}$ long $-Z K 12.0$ ),

- track distance.

For the sake of comprehensive diagnostics, each of the sections No. 1.1 and No. 2.1 is represented by 701 samples, each of the sections No. 1.2 and No. 2.2 is represented by 2561 samples.
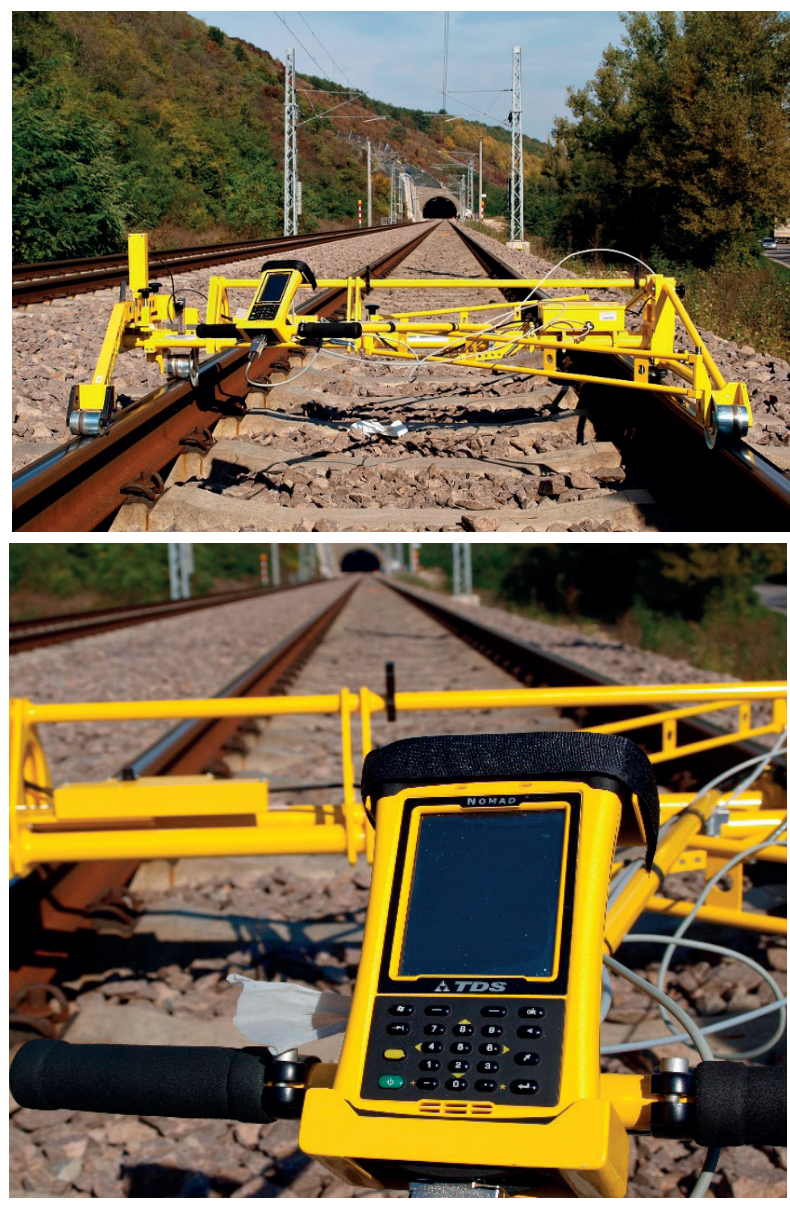

Fig. 2 Continuously measuring trolley $K R A B^{T M}$-Light (on the up) and computer Nomad (on the down)

4. Assessment of results of track alignment design and track geometry diagnostics

The assessment of results of the track alignment design and track geometry is carried out according to the valid technical standards and regulations [5]. The diagnostics of structure layout and track geometry of the track section:

- measurements before putting sections into operation (MSO) were made in 10.07. - 11.7.2012, 2.10 - 3.10.2012,

- first operational measurement (PO1) 09.04. - 10.04.2013, $21.04-22.04 .2013$, 


\section{COMMNICOIIONS}

The deviations of the relative geometric parameters of the track for RP4 [5]

Table 1

\begin{tabular}{|c|c|c|c|c|c|c|c|}
\hline Measured parameter & \multicolumn{2}{|c|}{ Limit input deviations } & \multicolumn{2}{|c|}{ Operational deviations } & \multicolumn{2}{|c|}{ Limit operational deviations } & Note \\
\hline$R K(\mathrm{~mm})$ & -2 & 2 & -3 & 5 & -5 & 10 & - \\
\hline$Z R(\mathrm{~mm} / \mathrm{m})$ & \multicolumn{2}{|c|}{2} & \multicolumn{2}{|c|}{3} & \multicolumn{2}{|c|}{4} & - \\
\hline$P K(\mathrm{~mm})$ & -3 & 3 & -6 & 6 & -8 & 8 & - \\
\hline Measured parameter & \multicolumn{2}{|c|}{ Limit value } & \multicolumn{2}{|c|}{ Operational value } & \multicolumn{2}{|c|}{ Limit operational value } & Note \\
\hline \multirow{3}{*}{$\begin{array}{l}Z K(1: n) \\
\text { (mm / base) }\end{array}$} & \multicolumn{2}{|c|}{$\begin{array}{c}1: 250 \\
(7.2 ; 4.0)\end{array}$} & \multicolumn{2}{|c|}{$\begin{array}{c}1: 250 \\
(7.2 ; 4.0)\end{array}$} & \multicolumn{2}{|c|}{$\begin{array}{c}1: 167 \\
(10.8 ; 5.99)\end{array}$} & $\begin{array}{c}\text { on measuring base } \\
1.8 \mathrm{~m}\end{array}$ \\
\hline & \multicolumn{2}{|c|}{$\begin{array}{c}1: 832 \\
(7.2 ; 1.20)\end{array}$} & \multicolumn{2}{|c|}{ not evaluated } & \multicolumn{2}{|c|}{$\begin{array}{c}1: 250 \\
(24.0 ; 4.0)\end{array}$} & $\begin{array}{c}\text { on measuring base } \\
6.0 \mathrm{~m}\end{array}$ \\
\hline & \multicolumn{2}{|c|}{ not evaluated } & \multicolumn{2}{|c|}{ not evaluated } & \multicolumn{2}{|c|}{$\begin{array}{c}1: 333 \\
(36.0 ; 3.0)\end{array}$} & $\begin{array}{c}\text { on measuring base } \\
12.0 \mathrm{~m}\end{array}$ \\
\hline Measured parameter & \multicolumn{2}{|c|}{$\begin{array}{l}\text { Limit input relative } \\
\text { deviations }\end{array}$} & \multicolumn{2}{|c|}{$\begin{array}{c}\text { Relative operational } \\
\text { deviations }\end{array}$} & \multicolumn{2}{|c|}{$\begin{array}{c}\text { Limit operational relative } \\
\text { deviations }\end{array}$} & Note \\
\hline$V L, V P(\mathrm{~mm})$ & -3 & 3 & -6 & 6 & -8 & 8 & - \\
\hline$S L, S P(\mathrm{~mm})$ & -3 & 3 & -6 & 6 & -8 & 8 & - \\
\hline
\end{tabular}

- second operational measurement (PO2) 08.10. - 09.10.2013, 21.10. - 22.10.2013,

- third operational measurement (PO3) 25.5.2014 and 28.5.2014,

- fourth operational measurement (PO4) 29.10.2014.

The measured parameters were evaluated according to the limit input deviations for acceptance of works with the use of new material $(M S O)$ and according to the operational deviations and limit operational deviations (PO1, PO2, PO3 and PO4) in Table 1 [7].
The results of measurement before putting sections into operation (MSO) obtained by the spot method have been compared to operational measurements $(P O 1, P O 2, P O 3$ and $P O 4)$ and the differences are shown in Table 2 - measurement of gauge deviations $\triangle R K$ and Table 3 - measurement of cant deviations $P K$ [8] and [4].

The sections with the lowest quality shown by evaluation are the section of track No. 1 in the area of the southern portal and the section of track No. 2 in the area of the northern portal, where incidence of local errors is the highest. There is expected

Differences of measurement of $\triangle \mathrm{RK}$ - operational measurement (PO1, PO2, PO3, PO4) and measurement before putting sections into operation (MSO)

Table 2

\begin{tabular}{|c|c|c|c|c|c|c|c|c|}
\hline \multirow{2}{*}{ Track / section } & \multicolumn{9}{|c|}{ Differences of measurement $\triangle R K(\mathrm{~mm})$} \\
\cline { 2 - 10 } & \multicolumn{2}{|c|}{ PO1-MSO } & \multicolumn{2}{c|}{ PO2-MSO } & \multicolumn{2}{c|}{ PO3-MSO } & \multicolumn{2}{c|}{ PO4-MSO } \\
\cline { 2 - 10 } & max. & min. & max. & min. & max. & min. & max. & min. \\
\hline Track No. 1 / Section No. 1 & 1.2 & -1.0 & 0.7 & -1.0 & 2.1 & -0.9 & 1.1 & -1.0 \\
\hline Track No. 1 / Section No. 2 & 1.4 & -1.0 & 0.7 & -1.5 & 0.6 & -1.8 & 0.9 & -1.7 \\
\hline Track No. 2 / Section No. 1 & 0.8 & -2.7 & 0.5 & -2.5 & 0.5 & -2.8 & 0.4 & -1.5 \\
\hline Track No. 2 / Section No. 2 & 1.3 & -1.3 & 2.0 & -3.1 & 1.0 & -3.6 & 1.2 & -2.9 \\
\hline
\end{tabular}

Differences of measurement of PK - operational measurement (PO1, PO2, PO3, PO4) and measurement before putting sections into operation (MSO)

\begin{tabular}{|c|c|c|c|c|c|c|c|c|}
\hline \multirow{2}{*}{ Track / section } & \multicolumn{9}{|c|}{ Differences of measurement PK $(\mathrm{mm})$} \\
\cline { 2 - 10 } & \multicolumn{2}{|c|}{ PO1-MSO } & \multicolumn{2}{|c|}{ PO2-MSO } & \multicolumn{2}{c|}{ PO3-MSO } & \multicolumn{2}{c|}{ PO4-MSO } \\
\cline { 2 - 10 } & max. & min. & max. & min. & max. & min. & max. & min. \\
\hline Track No. 1 / Section No. 1 & 0.6 & -4.2 & -1.1 & -4.6 & 0.8 & -3.1 & -0.6 & -4.7 \\
\hline Track No. 1 / Section No. 2 & 1.8 & -2.0 & 1.1 & -3.8 & 3.3 & -4.4 & 1.4 & -4.1 \\
\hline Track No. 2 / Section No. 1 & 1.6 & -2.2 & 1.9 & -3.2 & 1.7 & -2.8 & 1.3 & -3.4 \\
\hline Track No. 2 / Section No. 2 & 2.0 & -4.5 & 2.2 & -4.4 & 2.3 & -4.9 & 1.2 & -2.9 \\
\hline
\end{tabular}


improvement of the quality of all sections after their maintenance [9] and [10].

The continuous method used for overall superevaluation of the test sections (so called "section evaluation") is, in accordance with [2], given by the quality number of the section evaluated $(Q N)$, and the quality mark $(Q M)$ of $S R$ parameters $(S L), R K, P K$ and $V R(V L)$.

The evaluation of the section by the number of quality $(Q N)$, calculated according to the equation:

$Q N=\sqrt{0,57 \cdot S D V_{R K}^{2}+1,6 \cdot S D V_{S R, S L}^{2}+1,6 \cdot S D V_{V R, V L}^{2}}$

where: $S D V_{R K}$ - Standard deviation of variable of track gauge,

$S D V_{S R, S L}$ - Standard deviation of variable of direction of the track,

$S D V_{P K}$ - Standard deviation of variable of cant,

$S D V_{V R, V L}$ - Standard deviation of variable of longitudinal track height.

where $S D V=\sqrt{\frac{1}{n-1} \sum_{i=1}^{n} x_{i}^{2}}(\mathrm{~mm})$ expresses irregular course of the track geometry parameter in the section evaluated, where:

$n$ - number of points measured after $0.25 \mathrm{~m}$,

$i$ - marking measuring point,

$x_{i}$ - dynamic component of the relevant quantity of track geometry (deviation from the center line in the wavelength range $1 \mathrm{~m}$ to $25 \mathrm{~m})$.

The evaluation of section according to quality marks shall be carried out according to the equation:

$Q M=\frac{\ln \frac{S D V}{b}}{m}$

where $b$ and $m$ are numerical constants determined on the basis of the SDV statistics of relevant parameter and speed zone.

Considering the Railways of the Slovak Republic, the results of the quality section evaluation of the track according to quality marks are indicative and additional and are not binding for the evaluation of $R K$ state. The measures which are set for individual intervals of quality marks are recommendatory according to Table 4 .

The scale of quality marks (QM) according to quality section evaluation [6]

Table 4

\begin{tabular}{|c|c|c|}
\hline Interval of quality marks & Verbal assessment of the section according to the quality mark & $\begin{array}{l}\text { Color of the quality mark } \\
\text { in printed output }\end{array}$ \\
\hline $0<Q M \leq 2$ & the state of track geometry is satisfactory in the section evaluated & no color marking \\
\hline $2<Q M \leq 3$ & $\begin{array}{l}\text { it is recommended to design the repair of track geometry in the section evaluated } \\
\text { into the maintenance work plan }\end{array}$ & green color \\
\hline $3<Q M<4$ & $\begin{array}{l}\text { it is recommended to perform the repair of the track geometry in the section } \\
\text { evaluated before the nearest inspection }\end{array}$ & violet color \\
\hline $4 \leq Q M \leq 6$ & $\begin{array}{l}\text { it is recommended to perform immediate measures in the section evaluated to } \\
\text { ensure the safety of operation }\end{array}$ & red color \\
\hline
\end{tabular}

Quality in section No. 1 in track No. 1

\begin{tabular}{|c|c|c|c|c|c|c|c|c|c|c|c|c|c|c|c|c|c|}
\hline \multirow[b]{2}{*}{ 兽 } & \multirow{2}{*}{ 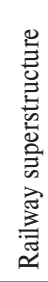 } & \multirow[b]{2}{*}{ 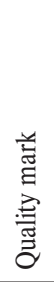 } & \multicolumn{3}{|c|}{ MSO } & \multicolumn{3}{|c|}{ PO1 } & \multicolumn{3}{|c|}{$\mathrm{PO} 2$} & \multicolumn{3}{|c|}{ PO3 } & \multicolumn{3}{|c|}{ PO4 } \\
\hline & & & 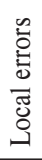 & ă & る & 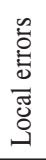 & ă & る & 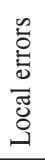 & ă & る & 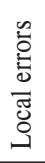 & ă & る & 范 & ă & る \\
\hline 102.360000 & \multirow[t]{2}{*}{$\bar{n}$} & $\stackrel{5}{a}$ & \multirow{2}{*}{10} & 2.07 & & \multirow{2}{*}{0} & 2.67 & \multirow{4}{*}{1.88} & \multirow[t]{2}{*}{0} & 2.25 & \multirow{4}{*}{1.89} & \multirow{2}{*}{0} & 1.88 & \multirow{4}{*}{1.96} & \multirow{2}{*}{0} & 3.12 & \multirow{4}{*}{2.36} \\
\hline 102.460500 & & 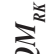 & & 1.73 & & & 1.73 & & & 1.73 & & & 1.74 & & & 1.70 & \\
\hline 102.480500 & 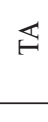 & $\Sigma^{\star}$ & & 1.88 & & & 2.00 & & 2 & 2.03 & & 4 & 2.03 & & & 2.05 & \\
\hline 102.535000 & 战 & $a^{5}$ & 0 & 2.50 & & 0 & 3.21 & & 1 & 3.37 & & 0 & 3.49 & & 0 & 3.50 & \\
\hline
\end{tabular}


Quality in section No. 2 in track No. 1

Table 6

\begin{tabular}{|c|c|c|c|c|c|c|c|c|c|c|c|c|c|c|c|c|c|}
\hline \multirow[b]{2}{*}{ 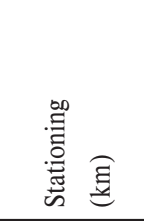 } & \multirow[b]{2}{*}{ 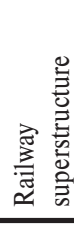 } & \multirow[b]{2}{*}{$\begin{array}{l}\text { 亲 } \\
\text { 意 } \\
\text { 亏े }\end{array}$} & \multicolumn{3}{|c|}{ MSO } & \multicolumn{3}{|c|}{ PO1 } & \multicolumn{3}{|c|}{ PO2 } & \multicolumn{3}{|c|}{$\mathrm{PO} 3$} & \multicolumn{3}{|c|}{ PO4 } \\
\hline & & & 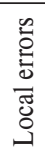 & ã & a & 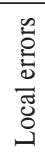 & à & z & 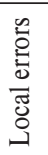 & ă & a & 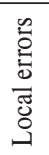 & ă & z & 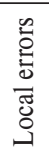 & ă & z \\
\hline 102.360000 & 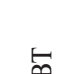 & $a^{\star \vdots}$ & 0 & 2.38 & & 0 & 2.37 & & 0 & 2.36 & & 0 & 2.40 & & 0 & 2.40 & \\
\hline 102.460500 & & दे & & 1.53 & & & 1.51 & & & 1.52 & & & 1.52 & & . & 1.52 & \\
\hline 102.480500 & $F$ & $z^{\star}$ & & 1.68 & & & 1.76 & & 0 & 1.80 & & & 1.86 & & 0 & 1.82 & \\
\hline 102.535000 & 点 & å & 1 & 2.06 & & 0 & 2.13 & & 0 & 2.19 & & 0 & 2.34 & & 0 & 2.35 & \\
\hline
\end{tabular}

Quality in section No. 1 in track No. 2

Table 7

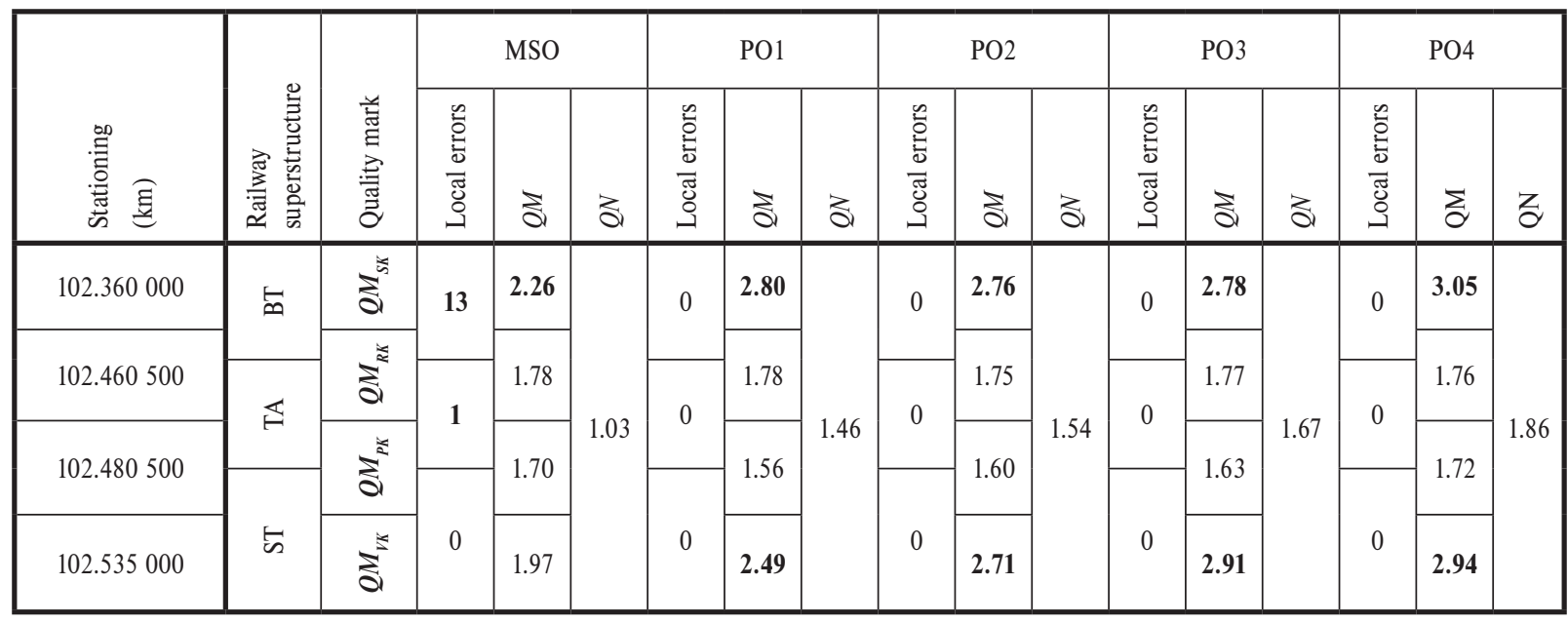

Quality in section No. 2 in track No. 2

Table 8

\begin{tabular}{|c|c|c|c|c|c|c|c|c|c|c|c|c|c|c|c|c|c|}
\hline \multirow[b]{2}{*}{ 莺 } & \multirow[b]{2}{*}{ 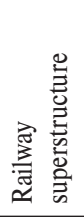 } & \multirow[b]{2}{*}{ 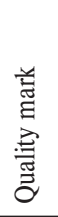 } & \multicolumn{3}{|c|}{ MSO } & \multicolumn{3}{|c|}{ P01 } & \multicolumn{3}{|c|}{$\mathrm{PO} 2$} & \multicolumn{3}{|c|}{ PO3 } & \multicolumn{3}{|c|}{ PO4 } \\
\hline & & & 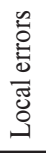 & ذ্ & a & 苛 & ఏ & $\vdots$ & 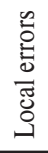 & ఏ & $\vdots$ & 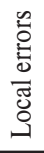 & ఏ & 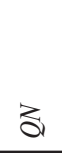 & 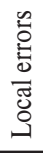 & $\overrightarrow{\mathbf{G}}$ & え \\
\hline 102.360000 & \multirow[t]{2}{*}{ 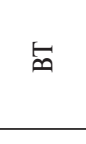 } & 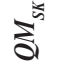 & \multirow[t]{2}{*}{9} & 2.50 & \multirow{4}{*}{1.31} & \multirow[t]{2}{*}{0} & 2.50 & \multirow{4}{*}{1.20} & \multirow[t]{2}{*}{0} & 2.50 & \multirow{4}{*}{1.21} & \multirow[t]{2}{*}{0} & 2.49 & \multirow{4}{*}{1.23} & \multirow[t]{2}{*}{0} & 2.50 & \multirow{4}{*}{1.24} \\
\hline 102.460500 & & $\Xi^{\approx}$ & & 1.72 & & & 1.60 & & & 1.58 & & & 1.58 & & & 1.58 & \\
\hline 102.480500 & 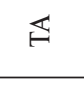 & $\Sigma^{\leftleftarrows}$ & 0 & 1.90 & & & 1.63 & & & 1.61 & & & 1.61 & & 0 & 1.62 & \\
\hline 102.535000 & 战 & $\stackrel{\$}{a}^{\lessgtr}$ & 7 & 2.39 & & 0 & 2.24 & & 0 & 2.29 & & 0 & 2.34 & & 0 & 2.36 & \\
\hline
\end{tabular}


The development of the track alignment design and track geometry of monitored sections is shown in Tables $5-8$.

The evaluation of deviations of the track alignment design and track geometry in velocity zone RP 4 according to [7 and 6] is calculated separately for sections with the ballasted track $(B T)$, for transition areas $(T A)$ and sections with the slab track structure $(S T)$.

From the overview of the track section quality it is clear that local errors noticed before putting sections into operation were eliminated by maintenance interventions carried out after input measurements. The section with the lowest quality shown by evaluation is the section of track No. 1 in the area of the southern portal, where occurence of local errors is the highest. This section also is of the lowest quality mark and number of quality. There is expected improvement of the track section quality after maintenance interventions.

\section{Conclusions}

The comparison of the results of diagnostics obtained by spot method and also by continuous method in the experimental sections shows direct connection. The section with the lowest quality shown by evaluation by both methods is the section No. 1 in the area of the southern portal.

The output of diagnostics is a set of information about the railway track quality. By using it, it is possible to predict further progress of the structure and then plan maintenance interventions.

The essential preconditions for the competitiveness of rail transport are sustainability and reliability of railway line operation. Only the development of various diagnostic methods and assessment of track alignment and track geometry can ensure the quality of the track geometry parameters, reduce maintenance costs, extend the service life of the structure and increase the competitiveness and attractiveness of railway lines in long- term perspective.

\section{Acknowledgement}

The paper contains partial results of the grant VEGA $1 / 0597 / 14$ "Analysis of methods used to measure the unconventional railway track construction from the point of view of accuracy and reliability".

\section{References}

[1] IZVOLT, L., SMALO, M.: Historical Development and Applications of Unconventional Structure of Railway Superstructure of the Railway Infrastructure of the Slovak Republic. Civil and Environmental Engineering, vol. 10, No. 2, 2014, pp. 79-94. EDIS: University of Zilina. ISSN 1336-5835.

[2] ZSR SR 103-8 (S): General requirements for the design, construction, repair, maintenance and acceptance of construction repair and maintenance works on the slab track construction (in Slovak). 2012, Bratislava: GR ZSR.

[3] IZVOLTOVA, J., PISCA, P., VILliM, A., MANCOVIC, M.: Precision Analysis of Height Measurements Realized on Ballastless Track. Communications - Scientific Letters of the University of Zilina, vol. 16, No. 4, 2014, p. 63-74. EDIS: University of Zilina. ISSN 1335-4205.

[4] SMALO, M., IZVOLT, L.: Assessment of Track Superstructure Quality - Spot and Method. Proc. of $11^{\text {th }}$ European Conference of Young Researchers and Scientists, TRANSCOM 2015, Zilina, June 2015, pp. 291-296. University of Zilina, 2015, ISBN 978-80554-1049-4.

[5] SESTAKOVA, J.: Quality of Slab Track Construction - Track Alignment Design and Track Geometry. Civil and Environmental Engineering, vol. 11, No. 1, 2015, pp. 2-9. EDIS: University of Zilina. ISSN 1336-5835.

[6] ZSR SR 103-7 (S): Measurement and Evaluation of Track Geometry by Measuring Trolley KRAB (in Slovak). 2008. Bratislava: GR ZSR.

[7] STN 73 6360: 1999. Track Alignment Design and Track Geometry of Normal-gauge Tracks and Amendment - part 1 (in Slovak). Bratislava: SUTN.

[8] IZVOLT, L. et al.: Monitoring of Sections of Non-conventional Constructions of the Railway Superstructure and the Transition Areas - $5^{\text {th }}$ and $6^{\text {th }}$ Stage. ZSR Modernization of Railway Track Nove Mesto nad Vahom - Puchov, km 100.500 to 159.100, part 24-32-01 Nove Mesto - Trencianske Bohuslavice (in Slovak), 2014. Department of Railway Engineering and Track Management: Faculty of Civil Engineering : University of Zilina.

[9] IZVOLTOVA, J., SESTAKOVA, J.: Analysis of the Impact of Traffic Load on the Slab Track Construction (in Slovak). Proc. of XII intern. conference Geodezia a kartografia v doprave. Praha : Cesky svaz geodetu a kartografu, 2014, pp. 168-176. ISBN 978-80-1202553-5.

[10] PLASEK, O., HRUZIKOVA, M., SVOBODA, R., BILEK, J.: Under Sleeper Pads in Railway Track. Communications - Scientific Letters of the University of Zilina, vol. 16, No. 4, 2014, p. 27-35. EDIS : University of Zilina ISSN 1335-4205. 